\title{
COVID-19: review of case reports
}

\author{
Yutaka Oda ${ }^{1}$ (D)
}

Received: 1 June 2020 / Accepted: 4 July 2020 / Published online: 12 July 2020

(c) Japanese Society of Anesthesiologists 2020

\begin{abstract}
Recently published case reports relating to anesthesia in patients with coronavirus disease (COVID-19) were reviewed. The diagnosis of COVID-19 was confirmed by positive results of reverse transcriptase polymerase chain reaction test for severe acute respiratory syndrome coronavirus 2 (SARS-CoV-2). Numerous reports handled emergency cesarean delivery. Primary symptoms and laboratory data of pregnant women with COVID-19 were similar to those of non-pregnant patients. Although the mortality rate is reported to be high after surgery in patients with COVID-19, cesarean delivery was successfully performed under regional anesthesia in most cases and postoperative course was favorable both in the parents and newborns. There is no direct evidence of vertical mother-to-child transmission of SARS-CoV-2; however, a diagnosis of COVID-19 was made in a newborn two hours after delivery from a pregnant woman with COVID-19, based on the increased immunoglobulin levels and deranged liver function, suggesting that its possibility cannot be completely eliminated. Emergency cerebral shunt reconstruction was performed repeatedly in an eight-month-old boy with COVID-19. The tracheal tube was removed in the operating room after surgery and postoperative course was uneventful. All the procedures should be performed in isolated operating rooms with medical staff with level-3 personal protection to ensure the safety of patients and health care providers.
\end{abstract}

Keywords Cesarean delivery · COVID-19 · Severe acute respiratory syndrome coronavirus 2 (SARS-CoV-2) · Vertical transmission

Severe acute respiratory syndrome coronavirus 2 (SARSCoV-2) is highly infectious [1, 2]. Because anesthesiologists and other medical providers are exposed to the primary routes of transmission such as respiratory droplets and aerosols [3, 4], we should be up-to-date about the preoperative management of infected patients to ensure the safety of both patients and health care providers. I will briefly review case reports recently published in our journal [5] as well as in others relating to coronavirus disease 2019 (COVID-19).

Several large studies have shown that old age ( $\geq 75$ years), male sex and comorbidities such as cardiac disease, chronic kidney disease are major risk factors of hospital admission and critical condition [6-8], although the reason for the sex difference is not clear. Concerning surgery, an international, multicenter cohort study demonstrated that male sex, age 70 years or older, American Society of Anesthesiologists

Yutaka Oda

yutakaodayutaka@gmail.com

1 Department of Anesthesiology, Osaka City Juso Hospital, 2-12-27, Nonaka-kita, Yodogawa-ku, Osaka 532-0034, Japan grades 3-5, malignant disease, emergency and major surgery are associated with high mortality rate within 30 days after surgery in patients with COVID-19 [9]. Accordingly, elective surgery should be postponed, and clinical emergency should be balanced against resource availability [10].

Pregnant women were particularly susceptible to respiratory pathogens and severe acute respiratory syndrome (SARS) caused by a coronavirus (SARS-CoV) [11, 12]. Although SARS-CoV-2 has up to $85 \%$ sequence similarity with SARS-CoV [13], pregnant women with COVID-19 in recent studies had fewer adverse maternal and neonatal complications and outcomes than would be anticipated for those with previously reported SARS infection [14]. Chen et al. [15] retrospectively examined clinical course and intrauterine vertical transmission potential of nine pregnant women (26-40 years) with laboratory-confirmed COVID19 pneumonia admitted to Zhongnan Hospital of Wuhan University between January 20 and 31, 2020. Primary symptoms were fever in seven patients, cough in four patients, while all were given oxygen support. All patients underwent cesarean delivery in their third trimester, although the 
details are not reported. Apgar scores were 8-9 and 9-10 at 1 and $5 \mathrm{~min}$, respectively. None of them developed severe pneumonia postoperatively. Amniotic fluid, cord blood, neonatal throat swab and breastmilk samples from six patients were all negative for SARS-CoV-2 by reverse transcription polymerase chain reaction (RT-PCR). The authors suggested that pregnant women with COVID-19 pneumonia showed a similar pattern of clinical characteristics to non-pregnant adult patients $[3,16]$.

Previous studies also showed that mother-to-child vertical transmission of COVID-19 is unlikely in 10 neonates born to mothers with confirmed COVID-19 [17], as being referred to by interim guidance [18]. However, Dong et al. [19] reported that the levels of SARS-CoV-2 IgG, IgM, cytokines as well as a white blood cell count were elevated in an infant $2 \mathrm{~h}$ after cesarean delivery from a mother with COVID-19 infection. Despite the negative results from repeated RT-PCR tests taken from $2 \mathrm{~h}$ to 16 days of age, the possibility of intrauterine transmission cannot be eliminated.

Wang et al. [20] reported a case of neonate COVID19. A 34-year-old pregnant woman presented to a hospital in Wuhan for fever. Based on a suspicious diagnosis of COVID-19 pneumonia according to the blood test data and typical computed tomography (CT) findings, emergency cesarean delivery was performed uneventfully. Her pharyngeal swab sampled for SARS-CoV-2 reported as positive after surgery. The result of pharyngeal swab collected $36 \mathrm{~h}$ after delivery from the infant was also positive for SARS$\mathrm{CoV}-2$, while a complete set of pediatric virus results was all negative. Combined with lymphopenia and deranged liver function, the diagnosis of COVID-19 was made for the newborn. Although cord blood, placental specimens obtained during surgery and breast milk sample were negative for SARS-CoV-2, the possibility of vertical intrauterine transmission of SARS-CoV-2 cannot be ruled out. Based on this experience, the authors emphasized the importance to keep all of the specimens of SARS-CoV-2-infected and suspected pregnant women and their newborns, including pharyngeal swabs, peripheral blood, placental tissue after delivery, amniotic fluid, cord blood, newborn pharyngeal swabs, and breast milk, for in-depth study and continuous follow-up observation.

Without detailed statistics, 35 cases with confirmed COVID-19 underwent emergency cesarean delivery in Wuhan Union Hospital from January 23 to February 20, 2020. Xia et al. [21] reported emergency cesarean delivery of a 27-year-old woman at 36 weeks and 5 days of gestation with COVID-19 pneumonia. After hospitalization for fever, her respiratory condition worsened as oxygen saturation was $92-93 \%$ in ambient air, and fetal movement was reduced 4 days later. Preoperative thoracic $\mathrm{CT}$ scan indicated the typical manifestations of COVID-19 including multiple patchy lung consolidation bilaterally and ground-glasslike opacities around the border and the subpleural distribution. The SARS-CoV-2 test was positive by RT-PCR. She underwent emergency cesarean delivery under spinal anesthesia with epidural intubing in an operating room where thirdlevel measures of medical protection were implemented. Although cough and tachycardia interfered with surgery, a healthy infant weighing 3,100 g was delivered, with Apgar scores of 9-10 at 1 and $5 \mathrm{~min}$. The results of nucleic acid test for SARS-CoV-2 were negative in oropharyngeal swabs of the mother and newborn on the third day after surgery.

Chen et al. [22] reported a 27-year-old pregnant woman at 36 weeks of gestation who was admitted to the Renmin Hospital of Wuhan University with fever, dry cough and fatigue. Results of her RT-PCR test for SARS-CoV-19 were positive. Because the findings of CT scan rapidly deteriorated within 2 days, she underwent elective cesarean delivery without complications, although the details of anesthesia were unknown. The RT-PCR for SARS-CoV-19 was negative in the neonate.

The same authors reported a case series of 17 parturients with COVID-19, including two doctors who had been in contact with affected patients, undergoing cesarean delivery from January 30 to February 23, 2020 [23]. All these patients were in a stable condition during pregnancy. Although thoracic CT demonstrated typical COVID-19 findings in all parturients, nine of them did not have common symptoms such as fever and cough. Five had lymphopenia, seven had elevated C-reactive protein level, but no abnormalities in alanine aminotransferase, aspartate aminotransferase, blood urea nitrogen and creatinine preoperatively.

They received either continuous epidural $(n=14)$ or general $(n=3)$ anesthesia with routine monitoring. General anesthesia was performed only in emergency cases. It was induced with rapid inhalation induction with $8 \%$ sevoflurane in $100 \%$ oxygen while cricoid pressure was continuously applied, followed by administration of lidocaine, remifentanil and succinylcholine for tracheal intubation. Sevoflurane was switched to propofol after delivery. Apgar scores were 7-9 and 9-10 at 1 and 5 min, respectively. No intrapartum death, neonatal death, or serious neonatal asphyxia was observed. The newborns were sent to the neonatal intensive care unit and were isolated from mothers. The results of RTPCR for SARS-CoV-2 were negative in both the newborns and in the medical staffs.

Notably, the procedure of patients' transportation and preparation of the operating room are explained in detail in this report. Patients were transferred from the isolation ward to an isolated, negative pressure operating room by a negative pressure isolation transfer cabin. All medical staffs used biosafety level-3 protective medical equipment during surgery. The anesthesiologists wore a gown with a powered air-purifying respirator for patients who received general anesthesia and endotracheal intubation following a 
recommendation [24], although there is no definitive evidence that powered air-purifying respirators reduce the likelihood of viral transmission in the setting of potential airborne spread. The authors concluded that the ideal timing of cesarean delivery is still crucial to ensure maternal and fetal safety, and recommend neuraxial anesthesia wherever possible, based on its reducing the possibility of exacerbating pulmonary complications accompanied with intubation.

Although the central nervous system lesions such as meningitis or cerebral hemorrhage have not been reported after spinal anesthesia for cesarean delivery in patients with COVID-19, postoperative neurological symptoms should be carefully observed because genome sequences were detected in the brain in autopsied samples from patients with SARS$\mathrm{CoV}$, previously pandemic in worldwide [25] and encephalitis/meningitis was recently reported in a patient with COVID-19 [26].

Zhong et al. [27] also reported safely performed spinal anesthesia for cesarean delivery, with stable blood pressure, heart rate and oxygen saturation, in 45 women with radiologically confirmed COVID-19 requiring supplemental oxygen. Notably, of the 44 anesthesiologists who had direct contact with patients, the results of RT-PCR for SARS-CoV-2 were positive in 1 of 37 who wore level 3 personal protective equipment (PPE), and in 4 of 7 anesthesiologists who wore level 1 PPE, postoperatively.

Du et al. [5] described the details of emergency cesarean delivery of a COVID-19-confirmed woman at the Affiliated Hospital of Xi' an Jiaotong University, with a review of previous publications of coronavirus-related cesarean delivery including Middle East Respiratory Syndromes. Despite a lack of findings in thoracic CT scan, remarkable leukocytosis as well as lymphopenia were noted preoperatively. Combined spinal and epidural anesthesia was safely performed. The mother and infant were discharged on the fifth postoperative day, after confirming negative RT-PCR for both. Facilities, equipment as well as anesthesia-related personnel to prevent infection have been described in detail.

Although few pediatric cases with COVID-19 are reported in relation to anesthesia, preparation of both the operating room and medical staffs is almost the same required for adult patients [28, 29]. Only one parent is allowed to accompany the child to the operating room for induction and should leave the room as soon as the child is asleep. Both the child and the parent are required to wear a surgical face mask prior to entering the operating room. Rapid sequence intubation to avoid bag-mask ventilation and closed breathing systems are recommended as in adults. Avoid forced-air warming blankets as they may aerosolize contaminants including viral product [30].

Carrabba et al. [31] reported cerebral shunt revision under general anesthesia in an 8-month-old male who presented with a dry cough. His chest XP was normal, but nasopharyngeal swab test was positive for SARS-CoV-2. Although he required repeated surgery for shunt dysfunction during 4 days, tracheal tube was removed promptly after each of the procedures and the neurosurgical course was favorable.

El Kassas et al. [32] reported emergency endoscopic variceal band ligation in a COVID-19 patient presented with hematemesis during mechanical ventilation. A 59-year-old male was transferred to their hospital with a diagnosis of COVID-19 infection by RT-PCR. He was vitally stable upon admission with mild dyspnea and cough. Two days after starting treatment, he developed pulmonary edema and was admitted to the ICU. He required tracheal intubation and mechanical ventilation 12 days after admission to the ICU. Two days later hematemesis occurred. A medical team consisting of an endoscopist, anesthesiologist and nurse performed endoscopic band ligation at the patient's bedside in the ICU. Propofol bolus $80 \mathrm{mg}$, followed by continuous infusion of a total dose of $120 \mathrm{mg}$ in $30 \mathrm{~min}$ was used. The patient was weaned from mechanical ventilation 2 days later.

In conclusion, postoperative 30-day mortality is high in male patients, $\geq 70$ years, with ASA PS $\geq 3$, malignant disease and after emergency surgery. Pregnant women with COVID-19 showed a similar pattern of clinical characteristics to non-pregnant adult patients. Neuraxial anesthesia is recommended for cesarean delivery if possible. When endotracheal intubation is indicated in emergency cases, use a rapid sequence induction to avoid cough and bag-mask ventilation.

\section{References}

1. Guan WJ, Ni ZY, Hu Y, Liang WH, Ou CQ, He JX, Liu L, Shan H, Lei CL, Hui DSC, Du B, Li LJ, Zeng G, Yuen KY, Chen RC, Tang CL, Wang T, Chen PY, Xiang J, Li SY, Wang JL, Liang ZJ, Peng YX, Wei L, Liu Y, Hu YH, Peng P, Wang JM, Liu JY, Chen Z, Li G, Zheng ZJ, Qiu SQ, Luo J, Ye CJ, Zhu SY, Zhong NS. Clinical characteristics of coronavirus disease 2019 in China. N Engl J Med. 2020;382:1708-20.

2. Wang D, Hu B, Hu C, Zhu F, Liu X, Zhang J, Wang B, Xiang $\mathrm{H}$, Cheng Z, Xiong Y, Zhao Y, Li Y, Wang X, Peng Z. Clinical characteristics of 138 hospitalized patients with 2019 novel coronavirus-infected pneumonia in Wuhan, China. JAMA. 2020;323:1061-9.

3. Li Q, Guan X, Wu P, Wang X, Zhou L, Tong Y, Ren R, Leung KSM, Lau EHY, Wong JY, Xing X, Xiang N, Wu Y, Li C, Chen Q, Li D, Liu T, Zhao J, Liu M, Tu W, Chen C, Jin L, Yang R, Wang Q, Zhou S, Wang R, Liu H, Luo Y, Liu Y, Shao G, Li H, Tao Z, Yang Y, Deng Z, Liu B, Ma Z, Zhang Y, Shi G, Lam TTY, Wu JT, Gao GF, Cowling BJ, Yang B, Leung GM, Feng Z. Early transmission dynamics in Wuhan, China, of novel coronavirusinfected pneumonia. N Engl J Med. 2020;382:1199-207.

4. Yamakage M. Anesthesia in the times of COVID-19. J Anesth. 2020. https://doi.org/10.1007/s00540-020-2798-4. 
5. Du Y, Wang L, Wu G, Lei X, Li W, Lv J. Anesthesia and protection in an emergency cesarean section for pregnant woman infected with a novel coronavirus: case report and literature review. J Anesth. 2020. https://doi.org/10.1007/s0054 0-020-2796-6.

6. Petrilli CM, Jones SA, Yang J, Rajagopalan H, O'Donnell L, Chernyak Y, Tobin KA, Cerfolio RJ, Francois F, Horwitz LI. Factors associated with hospital admission and critical illness among 5279 people with coronavirus disease 2019 in New York City: prospective cohort study. BMJ. 2020;369:m1966.

7. Docherty AB, Harrison EM, Green CA, Hardwick HE, Pius R, Norman L, Holden KA, Read JM, Dondelinger F, Carson G, Merson L, Lee J, Plotkin D, Sigfrid L, Halpin S, Jackson C, Gamble C, Horby PW, Nguyen-Van-Tam JS, Ho A, Russell CD, Dunning J, Openshaw PJ, Baillie JK, Semple MG, Investigators IC. Features of 20133 UK patients in hospital with Covid-19 using the ISARIC WHO Clinical Characterisation Protocol: prospective observational cohort study. BMJ. 2020;369:m1985.

8. Chen T, Wu D, Chen H, Yan W, Yang D, Chen G, Ma K, Xu D, Yu H, Wang H, Wang T, Guo W, Chen J, Ding C, Zhang X, Huang J, Han M, Li S, Luo X, Zhao J, Ning Q. Clinical characteristics of 113 deceased patients with coronavirus disease 2019: retrospective study. BMJ. 2020;368:m1091.

9. COVIDSurg Collaborative. Mortality and pulmonary complications in patients undergoing surgery with perioperative SARSCoV-2 infection: an international cohort study. Lancet. 2020. https ://doi.org/10.1016/s0140-6736(20)31182-x.

10. COVIDSurg Collaborative. Global guidance for surgical care during the COVID-19 pandemic. Br J Surg. 2020. https://doi. org/10.1002/bjs.11646.

11. Ramsey PS, Ramin KD. Pneumonia in pregnancy. Obstet Gynecol Clin N Am. 2001;28:553-69.

12. Wong SF, Chow KM, Leung TN, Ng WF, Ng TK, Shek CC, Ng PC, Lam PW, Ho LC, To WW, Lai ST, Yan WW, Tan PY. Pregnancy and perinatal outcomes of women with severe acute respiratory syndrome. Am J Obstet Gynecol. 2004;191:292-7.

13. Zhou P, Yang XL, Wang XG, Hu B, Zhang L, Zhang W, Si HR, Zhu Y, Li B, Huang CL, Chen HD, Chen J, Luo Y, Guo H, Jiang RD, Liu MQ, Chen Y, Shen XR, Wang X, Zheng XS, Zhao K, Chen QJ, Deng F, Liu LL, Yan B, Zhan FX, Wang YY, Xiao GF, Shi ZL. A pneumonia outbreak associated with a new coronavirus of probable bat origin. Nature. 2020;579:270-3.

14. Qiao J. What are the risks of COVID-19 infection in pregnant women? Lancet. 2020;395:760-2.

15. Chen H, Guo J, Wang C, Luo F, Yu X, Zhang W, Li J, Zhao D, Xu D, Gong Q, Liao J, Yang H, Hou W, Zhang Y. Clinical characteristics and intrauterine vertical transmission potential of COVID-19 infection in nine pregnant women: a retrospective review of medical records. Lancet. 2020;395:809-15.

16. Huang C, Wang Y, Li X, Ren L, Zhao J, Hu Y, Zhang L, Fan G, Xu J, Gu X, Cheng Z, Yu T, Xia J, Wei Y, Wu W, Xie X, Yin W, Li H, Liu M, Xiao Y, Gao H, Guo L, Xie J, Wang G, Jiang R, Gao Z, Jin Q, Wang J, Cao B. Clinical features of patients infected with 2019 novel coronavirus in Wuhan, China. Lancet. 2020;395:497-506.

17. Zhu H, Wang L, Fang C, Peng S, Zhang L, Chang G, Xia S, Zhou W. Clinical analysis of 10 neonates born to mothers with 2019nCoV pneumonia. Transl Pediatr. 2020;9:51-60.

18. Poon LC, Yang H, Dumont S, Lee JCS, Copel JA, Danneels L, Wright A, Costa FDS, Leung TY, Zhang Y, Chen D, Prefumo F. ISUOG Interim Guidance on coronavirus disease 2019 (COVID19) during pregnancy and puerperium: information for healthcare professionals-an update. Ultrasound Obstet Gynecol. 2020;55:848-62.
19. Dong L, Tian J, He S, Zhu C, Wang J, Liu C, Yang J. Possible vertical transmission of SARS-CoV-2 from an infected mother to her newborn. JAMA. 2020;323:1846-8.

20. Wang S, Guo L, Chen L, Liu W, Cao Y, Zhang J, Feng L. A case report of neonatal COVID-19 infection in China. Clin Infect Dis. 2020. https://doi.org/10.1093/cid/ciaa225.

21. Xia H, Zhao S, Wu Z, Luo H, Zhou C, Chen X. Emergency Caesarean delivery in a patient with confirmed COVID-19 under spinal anaesthesia. Br J Anaesth. 2020;124:e216-8.

22. Chen R, Chen J, Meng QT. Chest computed tomography images of early coronavirus disease (COVID-19). Can J Anaesth. 2020;67:754-5.

23. Chen R, Zhang Y, Huang L, Cheng BH, Xia ZY, Meng QT. Safety and efficacy of different anesthetic regimens for parturients with COVID-19 undergoing Cesarean delivery: a case series of 17 patients. Can J Anaesth. 2020;67:655-63.

24. Wax RS, Christian MD. Practical recommendations for critical care and anesthesiology teams caring for novel coronavirus (2019nCoV) patients. Can J Anaesth. 2020;67:568-76.

25. Gu J, Gong E, Zhang B, Zheng J, Gao Z, Zhong Y, Zou W, Zhan J, Wang S, Xie Z, Zhuang H, Wu B, Zhong H, Shao H, Fang W, Gao D, Pei F, Li X, He Z, Xu D, Shi X, Anderson VM, Leong AS. Multiple organ infection and the pathogenesis of SARS. J Exp Med. 2005;202:415-24.

26. Moriguchi T, Harii N, Goto J, Harada D, Sugawara H, Takamino J, Ueno M, Sakata H, Kondo K, Myose N, Nakao A, Takeda M, Haro H, Inoue O, Suzuki-Inoue K, Kubokawa K, Ogihara S, Sasaki T, Kinouchi H, Kojin H, Ito M, Onishi H, Shimizu T, Sasaki Y, Enomoto N, Ishihara H, Furuya S, Yamamoto T, Shimada $\mathrm{S}$. A first case of meningitis/encephalitis associated with SARS-Coronavirus-2. Int J Infect Dis. 2020;94:55-8.

27. Zhong Q, Liu YY, Luo Q, Zou YF, Jiang HX, Li H, Zhang JJ, Li Z, Yang X, Ma M, Tang LJ, Chen YY, Zheng F, Ke JJ, Zhang ZZ. Spinal anaesthesia for patients with coronavirus disease 2019 and possible transmission rates in anaesthetists: retrospective, singlecentre, observational cohort study. Br J Anaesth. 2020;124:670-5.

28. Thampi S, Yap A, Fan L, Ong J. Special considerations for the management of COVID-19 pediatric patients in the operating room and pediatric intensive care unit in a tertiary hospital in Singapore. Paediatr Anaesth. 2020. https://doi.org/10.1111/ pan.13863.

29. Greenland JR, Michelow MD, Wang L, London MJ. COVID-19 infection: implications for perioperative and critical care physicians. Anesthesiology. 2020;132:1346-61.

30. Francom CR, Javia LR, Wolter NE, Lee GS, Wine T, Morrissey T, Papsin BC, Peyton JM, Matava CT, Volk MS, Prager JD, Propst EJ. Pediatric laryngoscopy and bronchoscopy during the COVID-19 pandemic: a four-center collaborative protocol to improve safety with perioperative management strategies and creation of a surgical tent with disposable drapes. Int J Pediatr Otorhinolaryngol. 2020;134:110059.

31. Carrabba G, Tariciotti L, Guez S, Calderini E, Locatelli M. Neurosurgery in an infant with COVID-19. Lancet. 2020;395:e76.

32. El Kassas M, Al Shafie A, Abdel Hameed AS, Mahdi M. Emergency endoscopic variceal band ligation in a COVID-19 patient presented with hematemesis while on mechanical ventilation. Dig Endosc. 2020. https://doi.org/10.1111/den.13694.

Publisher's Note Springer Nature remains neutral with regard to jurisdictional claims in published maps and institutional affiliations. 